\title{
Reduced Vitamin D Levels and Iron Deficiency Anaemia in Pregnant Women: An Evolving Correlation
}

\author{
Roopa Satyanarayan Basutkar ${ }^{1}$, Thomas Eipe $^{1}$, Tenzin Tsundue', Divya Perumal ${ }^{2}$, Sivasankaran Ponnusankar ${ }^{1, *}$ \\ 'Department of Pharmacy Practice, JSS College of Pharmacy, Udhagamandalam-643001, JSS Academy of Higher Education and Research, Mysuru, INDIA. \\ ${ }^{2}$ Govt. District Headquarters Hospital, Udhagamandalam-643 001. The Nilgiris, INDIA.
}

\begin{abstract}
Aim: To elucidate correlation between serum vitamin $D$ levels and iron status in pregnant women and to generate hypothesis for supplementation of vitamin D in iron deficient patients. Methods: It is a prospective observational study of 101 pregnant women, recruited at the Government District Headquarters Hospital, Udagamandalam. Descriptive analysis was performed for the demographic characteristics. Spearman's correlation test was used to determine the strength of correlation between vitamin $D$ and the complete blood count parameters. Each outcome variables whose levels were with a $P(<0.05)$ is significant. Results: For the 101 recruited patients, the mean haemoglobin level was $9.35 \pm 0.89 \mathrm{~g} / \mathrm{dL}$, iron at $73.0 \pm 15.3$ microgram $/ \mathrm{dL}$, ferritin at $13.0 \pm 3.8 \mathrm{ng} / \mathrm{mL}$. There was a moderate positive correlation observed between vitamin $D$ and haemoglobin $\left(r_{s}=0.49\right.$, $\mathrm{n}=101 p<0.001)$. A strong positive correlation was noted between vitamin $\mathrm{D}$ and iron $\left(r_{s}=0.788, p<0.000\right)$, transferrin $\left(r_{s}=0.740, p<0.001\right)$, ferritin $\left(r_{s}=0.783, p<0.001\right)$, hematocrit $\left(r_{s}=0.729, p<0.001\right)$. A strong negative correlation was noted for TIBC $\left(r_{s}=-0.744, p<0.000\right)$. Conclusion: In this
\end{abstract}

population of pregnant women, it is suggestive that the low vitamin $D$ levels are correlated with lower haemoglobin and ferritin levels. Further investigations needs to be conducted to elucidate whether there is a direct causal effect of vitamin D deficiency and iron deficiency anaemia.

Key words: Anaemia, Vitamin D, Haemoglobin, Serum Ferritin, Serum Vitamin D, Pregnancy.

Correspondence

Dr Sivasankaran Ponnusankar, Professor and Head, Department of Pharmacy Practice, JSS College of Pharmacy, Rocklands, Udhagamandalam -643001, The Nilgiris, Tamilnadu, INDIA

Phone: +919489613428

Email: ponnusankarsivas@gmail.com

DOI: 10.5530/jyp.2019.11.19

\section{INTRODUCTION}

Vitamin D deficiency or insufficiency has affected over one billion people worldwide. Based upon various factors like lifestyle, climatic conditions, sun exposure and diet the supplementation of vitamin D should be determined. ${ }^{1}$ Iron deficiency anemia (IDA) is estimated to affect more than two billion people globally. In India, the prevalence of IDA stood at 53\% in the year 2015-2016 for women aged between 15-49 years, due to the progressive loss of iron through menstruation. This requirement is higher during pregnancy because of the increased demand of nutrients as well as the increased volume of blood needed for the growth of the fetus. ${ }^{2}$

Iron plays a vital role in maintaining the homeostasis of the body via anemia and the net shortage of energy production and transport. The global task force for the management of IDA has largely been directed towards iron supplementation. ${ }^{3}$ Recent evidence suggests an association between the iron and vitamin D pathways. Vitamin D deficiency has been reported to be responsible for the up regulation of Hepcidin, a molecule responsible for the down regulation of iron absorption through less iron absorption and iron entrapment within the tissues. Additionally, Vitamin D receptors are present in almost all the cells including the bone marrow progenitor cells as well. ${ }^{4}$ Recent evidence has demonstrated the effect of calcitriol leading to the increased expression of the erythropoietin receptors there by stimulating erythropoiesis. ${ }^{5}$ A study by Suh YJ et al. in Korean women concluded that vitamin D levels were found to affect IDA negatively. ${ }^{6}$ Similarly, Qader EA et al. conducted a case control study in Erbil Iraq and the results indicated a significant moderate positive correlation between vitamin $\mathrm{D}$ and serum iron levels in children aged
1-5 years. ${ }^{7}$ A study by Lee JA et al. concluded an increased risk of iron deficiency anemia in healthy female children and adolescents who were vitamin D deficient. ${ }^{8}$ To evaluate the correlation between vitamin $\mathrm{D}$ and iron status in mild to moderate iron deficiency anaemic pregnant women attending Obstetrics and Gynaecology clinic.

\section{MATERIALS AND METHODS}

\section{Design and study population}

This is a prospective observational study. 101 pregnant women with $26^{\text {th }}$ to $28^{\text {th }}$ weeks of gestation were recruited between the months of September 2016 to February 2017 at Obstetrics and Gynecology Department of Government Head Quarters and Hospital, Udhagamandalam. The study was approved by the Institutional Review Board, JSS College of Pharmacy, Udhagamandalam (JSSCP/DPP/IRB/01/2016-17) before initiation.

\section{Inclusion criteria}

The inclusion criteria included pregnant women of age 18 years or greater, confirmed singleton pregnancy on or before 28 weeks of gestation or as defined through their last menstrual period or as determined through the ultra sound result, the ability of the women to provide the consent, not on vitamin $\mathrm{D}$ containing medications and iron deficiency anaemia with average haemoglobin level range of 10-10.9 and 7-9.9 g/dl, serum ferritin level $<12$ micro grams/dL, with no history of blood transfusion within the last 3 months, vitamin D levels less than $30 \mathrm{nmol} / \mathrm{L}$ or $12 \mathrm{ng} / \mathrm{ml}$. 


\section{Exclusion criteria}

The pregnant women with active thyroid diseases (eg: Graves disease, Hashimoto disease or thyroiditis) are excluded, but mothers on thyroid supplement with normal serologic parameters could participate in the study if they are without any other endocrine dysfunction. While the pregnant women with the pre-existing calcium or parathyroid conditions and one who requires chronic diuretic or cardiac medication therapy including calcium channel blockers or one who suffered chronic hypertension are excluded, the presence of seizure disorder, with history of haemolytic anaemia or thalassemia, with hepatic or renal insufficiency, history of peptic ulcer, esophagitis, gastritis or hiatus hernia, with family history of thalassemia, sickle cell anaemia or malabsorption syndrome, severe anaemia $(\mathrm{Hb}<7 \mathrm{~g} / \mathrm{L})$, presence of chronic haematological diseases, hereditary diseases of the blood and multiple pregnancies were also excluded. Moreover, patients with history of chronic blood loss and anaemia other than iron deficiency were not recruited. (Figure 1)

\section{Data collection}

A specially designed data collection form designed for the study was used to collect information on socio-economic and demographic characteristics: age, consanguineous marriage, education level, occupation, sun exposure details, daily physical activity, supplement intake, gravida, parity, history of abortion, while anthropometric measurements and

\section{0 patients with IDA were screened}

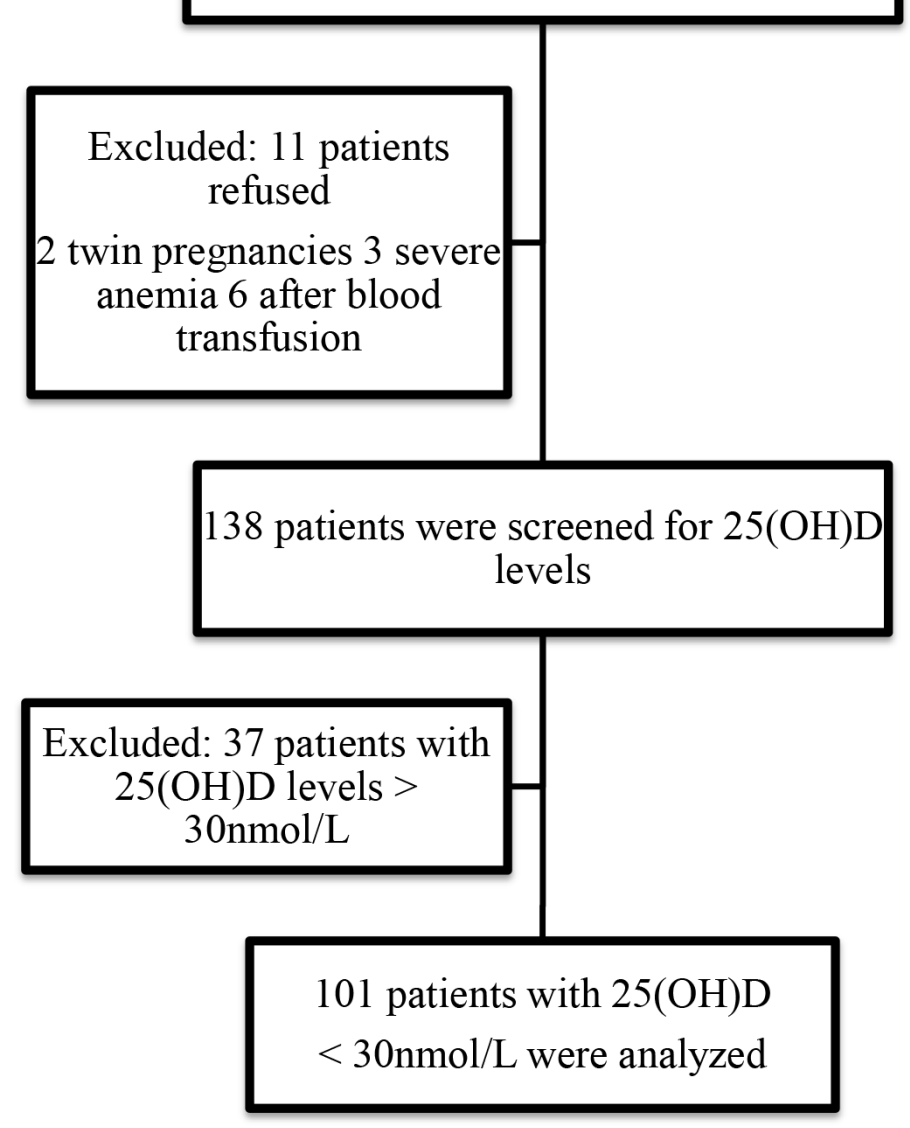

Figure 1: Study selection and flow chart of the study. blood samples were taken from the eligible pregnant women to assess serum vitamin $\mathrm{D}$, haemoglobin, red blood cells (RBC), haematocrit, ferritin, transferrin saturation, Total Iron Binding Capacity (TIBC), Mean Cell Volume (MCV), Mean Cell Haemoglobin (MCH) status.

\section{Laboratory measurement and definition}

Those pregnant women who provide the consent, the anthropometry measurement were performed, after which the venous blood $(5 \mathrm{ml})$ from pregnant women was drawn by venipuncture into a sterile tube (no anticoagulant) by a licensed laboratory technician and was centrifuged within 30 mins at room temperature. Serum was separated and frozen in several aliquots at $-40^{\circ} \mathrm{C}$ on the same day until analysed. The parameters haemoglobin, red blood cell count, platelet count, total count, haematocrit, $\mathrm{MCV}, \mathrm{MCH}$, Mean Corpuscular Hemoglobin Concentration (MCHC) were analysed at laboratory of Government Headquarters Hospital and the remaining parameters ferritin, Transferrin Saturation, Total Iron Binding Capacity (TIBC), vitamin D, serum iron and PTH were analysed at Thyrocare Laboratories, Mumbai India.

Haemoglobin was estimated using Drabkin's method, Ferritn using Fully Automated Bi-directionally Interfaced Chemi Luminescent Immuno Assay, Iron using Ferrozine method without deproteinization, Total Iron Binding Capacity (TIBC) using Spectrophotometric Assay, parathyroid hormone (PTH) using Fully Automated Chemi Luminescent Immuno Assay, 25( $\mathrm{OH})$ vitamin D using Immunoenzymetric Assay and percent transferrin saturation was derived from Iron and TIBC values. Complete blood count was estimated using fully automated haematology analyser. Iron deficiency anaemia was defined as haemoglobin level of 10-10.9 g/dl as mild anaemia, 7-9.9 g/dl as moderate anaemia and 4-6.9 g/dl as severe anaemia as per Indian Council of Medical Research (ICMR) guidelines. During pregnancy, $20 \mathrm{ng} / \mathrm{ml}$ of circulating vitamin D level is considered normal as per Institute of Medicine, while $30 \mathrm{ng} / \mathrm{ml}$ or more is considered as adequate by the Endocrine Society. According to the mathematical model suggested by Holles et al a circulating vitamin D $>40 \mathrm{ng} / \mathrm{ml}$ should be achieved during pregnancy.

\section{Statistical analysis}

Statistical analysis of the data was performed using the IBM SPSS statistical software (V.22.0; SPSS Inc, Chicago, Illinois, USA for windows) and continuous data were presented as mean \pm SD with 95\% CIs. Spearman's correlation was used to measure the strength and direction of correlation between iron status and vitamin D levels with significance at $P=0.05$.

\section{RESULTS}

For the 101 recruited patients, the mean age of the participants was $23.2 \pm 2.3$ years while mean BMI was $22.6 \pm 3.0 \mathrm{~kg} / \mathrm{m}^{2}$. Of these recruited patients, $21.8 \%$ had studied till undergraduate levels. However, $93.1 \%$ of the subjects were housewives and only $26.8 \%$ of the recruited patients had sun exposure for more than 30 mins a day. (Table 1). Table 2 represents the mean serum values for laboratory parameters that were assessed. The mean values of the serum parameters were as, haemoglobin at $9.35 \pm 0.89 \mathrm{~g} / \mathrm{dL}$, iron at $73.0 \pm 15.3 \mathrm{mg} / \mathrm{dL}$, TIBC at $445.2 \pm 43.3$ $\mathrm{mg} / \mathrm{dL}$, transferrin at $15.0 \% \pm 4.8 \%$, ferritin at $13.0 \pm 3.8 \mathrm{ng} / \mathrm{mL}, \mathrm{PTH}$ at $30.7 \pm 5.51 \mathrm{pg} / \mathrm{mL}$, platelets at $445.3 \pm 38.6 \times 10^{3} / \mathrm{mm}^{3}$, vitamin $\mathrm{D}$ at $16.5 \pm 5.8 \mathrm{ng} / \mathrm{mL}, \mathrm{RBCs}$ at $3.38 \pm 0.23 \times 10^{6} / \mathrm{mm}^{3}$ etc. Spearman's correlation was computed to assess the monotonic relationships between vitamin $\mathrm{D}$ and the recorded blood parameters to determine the strength of correlation and the direction of the monotonic relationships between variables as linearity of parameters are not always warranted.

There was a moderate positive correlation between vitamin $\mathrm{D}$ and hemoglobin $\left(\mathrm{r}_{\mathrm{s}}=0.49, \mathrm{n}=101 p<0.001\right)$ and a moderate negative correlation between vitamin $\mathrm{D}$ and platelets $\left(\mathrm{r}_{\mathrm{s}}=-0.486, \mathrm{n}=101, p<0.000\right)$. A strong 
Table 1: Sociodemographic data of studied patients.

\begin{tabular}{|c|c|}
\hline \multicolumn{2}{|c|}{ Education level, $\mathbf{n}(\%)$. Where $\mathrm{n}=101$. } \\
\hline Illiterate & $3(3)$ \\
\hline Primary & $5(5)$ \\
\hline Intermediate & $39(38.6)$ \\
\hline Secondary & $32(31.7)$ \\
\hline Under Graduate & $22(21.8)$ \\
\hline \multicolumn{2}{|c|}{ Occupation (\%) } \\
\hline Employed & $7(6.9)$ \\
\hline Housewife & $94(93.1)$ \\
\hline \multicolumn{2}{|c|}{ Consanguinity, n (\%) } \\
\hline First degree & $2(2.0)$ \\
\hline Second degree & $4(4.0)$ \\
\hline None & $95(94.1)$ \\
\hline \multicolumn{2}{|c|}{ Sun Exposure per day in minutes, $n(\%)$} \\
\hline$<15$ & $25(24.8)$ \\
\hline $15-30$ & $49(48.5)$ \\
\hline $30-60$ & $14(13.9)$ \\
\hline$>60$ & $13(12.9)$ \\
\hline \multicolumn{2}{|c|}{ Diet, n (\%) } \\
\hline Vegetarian & $5(5.0)$ \\
\hline Non-Vegetarian & $96(95)$ \\
\hline
\end{tabular}

Table 2: Base line statistics for 101 participants on sample blood parameters with Spearmen's correlation coefficient.

\begin{tabular}{cccccc}
\hline Measurement & $\begin{array}{c}\text { Mean } \pm \text { SD } \\
(\mathbf{n}=101)\end{array}$ & \multicolumn{2}{c}{$\begin{array}{c}\text { 95\% Confidence } \\
\text { Interval of the } \\
\text { Difference* }\end{array}$} & $\begin{array}{c}\text { Correlation } \\
\text { coefficient }\end{array}$ & $\begin{array}{c}P \\
\text { Value }\end{array}$ \\
\cline { 3 - 4 } & & Lower & Upper & & \\
\hline Hemoglobin & $9.3564 \pm .89982$ & 9.1788 & 9.5341 & 0.496 & 0.001 \\
Iron & $73.04950 \pm 15.30384$ & 70.0283 & 76.0707 & 0.788 & 0.000 \\
TIBC & $445.2673 \pm 43.33010$ & 436.7134 & 453.8212 & -0.744 & 0.000 \\
Transferrin & $15.00990 \pm 4.83010$ & 14.0564 & 15.9634 & 0.740 & 0.001 \\
Ferritin & $13.02574 \pm 3.82575$ & 12.2705 & 13.7810 & 0.783 & 0.003 \\
PTH & $30.7065 \pm 5.51376$ & 29.6180 & 31.7950 & 0.136 & 0.176 \\
Platelet count & $445.3069 \pm 38.66827$ & 437.6733 & 452.9405 & -0.486 & 0.000 \\
RBC & $3.3839 \pm 0.23816$ & 3.3368 & 3.4309 & 0.762 & 0.000 \\
Total Count & $8.5719 \pm 1.02458$ & 8.3696 & 8.7741 & 0.034 & 0.733 \\
Hematocrit & $33.3780 \pm 2.67439$ & 32.8501 & 33.9060 & 0.729 & 0.001 \\
MCV & $74.9564 \pm 3.93871$ & 74.1789 & 75.7340 & 0.706 & 0.005 \\
MCH & $28.0459 \pm 3.08419$ & 27.4371 & 28.6548 & 0.832 & 0.001 \\
MCHC & $33.1159 \pm 2.37302$ & 32.6475 & 33.5844 & 0.810 & 0.003 \\
VitD & $16.56851 \pm 5.88658$ & 15.4064 & 17.7306 & - & - \\
\hline
\end{tabular}

* Correlation is significant at the 0.05 level (2-tailed).

positive correlation was noted between vitamin $\mathrm{D}$ and red blood cells ( $\mathrm{rs}=0.762, p<0.005)$, iron $\left(\mathrm{r}_{\mathrm{s}}=0.788, p<0.000\right)$, transferrin $\left(\mathrm{r}_{\mathrm{s}}=0.740\right.$, $\mathrm{p}<0.001)$, ferritin $\left(\mathrm{r}_{\mathrm{s}}=0.783, \mathrm{p}<0.001\right)$, hematocrit $\left(\mathrm{r}_{\mathrm{s}}=0.729, p<0.001\right)$ and mean cell volume $\left(r_{s}=0.706, p<0.005\right)$. Similarly a strong negative correlation was noted for TIBC $\left(\mathrm{r}_{\mathrm{s}}=-0.744, p<0.000\right)$. Quite interestingly, we noted a very strong correlation between vitamin $\mathrm{D}$ and mean cell
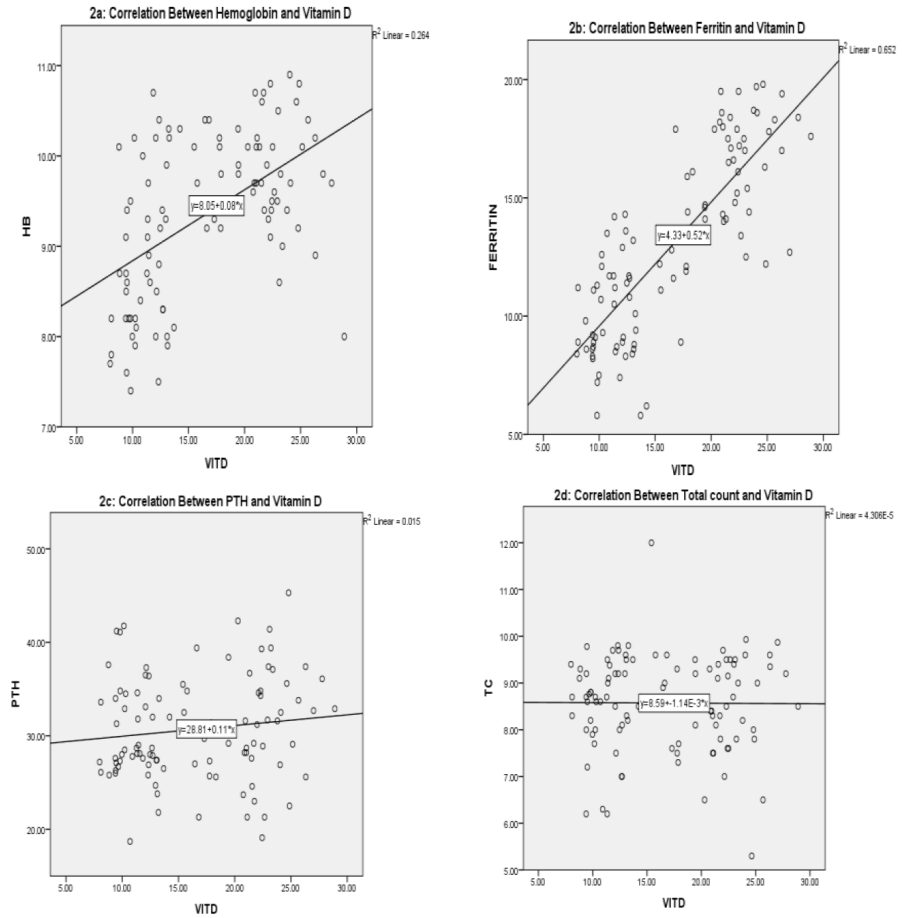

Figure 2: Scatter plot for vitamin D compared to various parameters.

2a: Vitamin D and Hemoglobin showing a positive linear correlation;

2b: Vitamin D and Ferritin showing a positive linear correlation.

2c: Vitamin D and PTH showing no correlation;

2d: Vitamin D and Total count showing no correlation.

hemoglobin $\left(r_{s}=0.832, p<0.001\right)$ and mean cell hemoglobin concentration $\left(r_{s}=0.810, p<0.003\right)$. The study did not find any statistically significant correlation for vitamin D against PTH $\left(\mathrm{r}_{\mathrm{s}}=0136, p<.176\right)$ and total count $\left(r_{s}=0.0034, p<0.733\right)$.

Graphs were drawn using a simple scatter plot, with a linear line fit in the total. For all the blood parameters with a significant correlation with vitamin $\mathrm{D}$, we noticed either a positive or a negative linear relationship. However, for the parameters (PTH and total count) having no significant correlation with vitamin D, a parallel line is obtained [Figure 2 (2a, $2 b$, $2 \mathrm{c}$ and $2 \mathrm{~d})$ ].

\section{DISCUSSION}

In developing countries, at least $18 \%$ of the global burden of disease is caused by complications of pregnancy and child birth leading to disability and death among women of reproductive age. This pattern of maternal death and disability is linked to the high prevalence of vitamin D deficiency. Every year, almost 8 million still births and early neonatal deaths occur. ${ }^{10-11}$

Though the mechanism of the association between vitamin D and IDA is not clear, vitamin $\mathrm{D}$ receptors in bone marrow affects marrow function. The levels of 1,25 hydroxyvitamin $\mathrm{D}$ (the active form of vitamin $\mathrm{D}$ ) are several hundred-fold higher in bone marrow compared with plasma. There is overall paucity of clinical studies investigating whether adequacy of vitamin D affects blood Hemoglobin ( $\mathrm{Hb}$ ) levels. ${ }^{12-14}$

The absorption and recycling of iron is under control of the hepcidinferroportin axis in humans. Iron is strictly regulated, because iron deficiency causes anemia and in excess promotes generation of reactive oxygen species, causing tissue injury and organ failure. In inflammatory states such as Chronic Kidney Disease (CKD), hepcidin antimicrobial 
peptide (referred to as hepcidin), the principal regulator of iron homeostasis is elevated. This elevated hepcidin, inhibits iron uptake from the gut and sequesters iron in the reticuloendothelial system. When macrophages engulf senescent red blood cells, hepcidin retains the iron in the macrophages by binds to its receptor ferroportin, causing its internalization and degradation. This prevents iron egress from macrophages and consequently affects normal recycling of the iron needed to support erythropoiesis. Recent investigations showed that vitamin D concentrations [assessed by serum 25-hydroxyvitamin D (25(OH)D)] are inversely associated with hepcidin concentrations and positively associated with hemoglobin and iron concentrations. ${ }^{12-14}$

Our study conducted in the population of pregnant women attending the Government Headquarter Hospital, Udhagamandalam highlights the potential correlation between vitamin $\mathrm{D}$ and iron deficiency anaemia. Net, only 101 subjects were presented for analysis. Apart from the prevalence of IDA in vitamin D deficient patients, IDA in itself may subject patients to vitamin $\mathrm{D}$ deficiency, as anemic subjects are less likely to obtain adequate sun exposure through indoors hospital admissions. Where, sun exposure is considered the natural source of vitamin $\mathrm{D} .{ }^{15}$ The synthesis of cholecalciferol from cholesterol is dependent on ultraviolet $\mathrm{B}$ (UVB) radiations of the sun, which in turn is followed by hydroxylation reactions in the liver and the kidneys for the active form, vitamin $\mathrm{D}_{3} \cdot{ }^{16}$

Patients with CKD were excluded from this study as kidneys remain the primary site for conversion of $25(\mathrm{OH}) \mathrm{D}$ to calcitriol $(1,25(\mathrm{OH}) 2 \mathrm{D})$ by the enzyme $1 \alpha$-hydroxylase, which declines as kidney disease progresses and renal mass decreases. ${ }^{17}$ Moreover, Gastro Intestinal diseases may interfere with the gut absorption of vitamin D. ${ }^{18}$ The purpose of exclusion of such comorbidities is to eliminate the confounding factors that may attribute to vitamin $\mathrm{D}$ deficiency and cannot be generalized to the population.

A study conducted in Northern United States found that 29.2\% and 54.1\% of black women and $45.6 \%$ and $46.8 \%$ black neonates were vitamin D deficient and insufficient, respectively and another $5 \%$ and $42.1 \%$ of white women and $9.7 \%$ and $56.4 \%$ of white neonates were vitamin D deficient and insufficient, respectively. ${ }^{19}$ Another study conducted in Boston found that found that $28 \%$ of women with serum $25(\mathrm{OH}) \mathrm{D}$ less than $37.5 \mathrm{nmol} /$ liter had a cesarean section, compared with only $14 \%$ of women with $25(\mathrm{OH}) \mathrm{D} 37.5 \mathrm{nmol} /$ liter or greater. ${ }^{20} \mathrm{~A}$ population-based study in Sydney, Australia examined the increased risk of neonatal vitamin D deficiency with maternal vitamin D deficiency (OR 17.2, 95\% CI 8.8-34.3) and birth weight was lower among infants of deficient vs. sufficient mothers: mean (SD) $3245 \mathrm{~g}$ (545) vs. $3453 \mathrm{~g}$ (555), $p<0 \cdot 001 .^{21}$

The outcome of this study depicts a high prevalence of vitamin D deficiency among pregnant women with iron deficiency anemia. A study by Chittari $\mathrm{V}$ et al. even postulated that vitamin $\mathrm{D}$ synthesis is directly initiated through exposure to sun radiation..$^{22}$ The extent of sun exposure to the presence of vitamin D deficiency is presented in Table 1 . The low levels of vitamin D in the Udhagamandalam population can be attributed to the low level of sun exposure, as $73.3 \%$ of the subjects had exposure to sun for even less than $30 \mathrm{~min}$ as $93.1 \%$ of our subjects were housewives and were associated with limited involvement of physical activity outdoors. Moreover, despite a high number (92.1\%) of literate populations, vitamin D deficiency was found prominent in the recruited subjects. Vitamin D deficient pregnant women presented with lower hemoglobin, lower serum iron levels, lower RBC, Hematocrit, MCV, $\mathrm{MCH}, \mathrm{MCHC}$ counts while higher platelet, TIBC and PTH levels. Although our study found a linear correlation between vitamin D deficiency and iron deficiency anemia, a direct causal relationship cannot be established as it warrants further randomized controlled trials with vitamin $\mathrm{D}$ supplementation.
Various conclusions and hypotheses can be drawn from the findings. It is quite evident from our statistical results that vitamin D is significantly associated with iron deficiency anaemia and the linked association may be attributed by the possible interlinked metabolism and biologic pathways as mentioned in the studies by Suh YJ et al. ${ }^{6}$ in Korean Women, Qader EA et al ${ }^{p}$ and Lee JA et al. ${ }^{8}$ in healthy female children and adolescents. These findings provide evidence suggesting that Vitamin D deficiency is common during pregnancy, which leads to adverse pregnancy outcome. Similar to the results observed in Qatar (17.8\%), vitamin D deficiency was higher in the US (24.8\%), the People's Republic of China $(24.2 \%)$, Canada (20.7\%) and Australia (21\%). ${ }^{11}$

A statistical correlation was not found between vitamin D and PTH $\left(r_{s}=0136, p<.176\right)$ and Total count $\left(r_{s}=0.0034, p<0.733\right)$. However, Lips et al, in his study demonstrated an interaction between calcium and vitamin $\mathrm{D}$, where the vitamin $\mathrm{D}$ plays a role in calcium transport in the intestine and fluctuations in calcium levels lead to the increase and decrease in PTH levels respectively. ${ }^{23}$ The findings of this study could not demonstrate this correlation as results may be influenced by sample size and majorly since our study is only based on the population of pregnant women attending the government hospitals Ooty and the climatic and the lifestyle pattern may vary with other populations. Causal relationship between vitamin $\mathrm{D}$ and anaemia cannot be elucidated, but the study supports the assumption that vitamin $\mathrm{D}$ deficiency is a potential risk factor for IDA. This is in agreement with the study conducted by Thomas CE et al. ${ }^{24}$ which demonstrated that maternal 25-hydroxyvitamin D $[25(\mathrm{OH})$ D] was positively associated with maternal haemoglobin at both mid-gestation and at delivery. These findings emphasize the need for screening multiple nutrient deficiencies during pregnancy which may help in decision making for selecting appropriate prenatal supplementation regimens for a better patient care in the light of risk vs benefit.

Certain limitations were faced due to the limited sample size and short duration of the study. An important limitation of our study was that maternal serum $25(\mathrm{OH}) \mathrm{D}$ levels were assessed by a single measurement during the early stage of pregnancy, which may not reflect the maternal $25(\mathrm{OH}) \mathrm{D}$ status during the entire pregnancy. However, a possible confounder as selection bias may have attributed in our observational study. The observational design of this study; as such, we could not ascertain or determine the neonatal outcomes of maternal 25(OH)D deficiency and also could not suggest any causal relationship, further hypotheses and therefore yet be generated and tested upon. In most countries, there is no monitoring of serum $25(\mathrm{OH}) \mathrm{D}$ levels during pregnancy for vitamin $\mathrm{D}$ deficiency. ${ }^{25}$ Previous studies of Bener et al. support these findings that vitamin D deficiency was more prevalent in Qatar and the population had less exposure to sun, although it is a sun-enriched population. ${ }^{26}$

The need and the role of vitamin $\mathrm{D}$ has a major impact on pregnancy outcomes that are quite clear through our results and the question to be raised now includes, whether to add vitamin $\mathrm{D}$ supplementation and the strength of the supplement safe enough for both the mother and the child for which various RCTs are required as for evidence. Vitamin D screening is an important aspect that requires more awareness and attention from prescribers and the other health care professionals. The high strength of correlation should therefore be significantly applied to the knowledge and the use for patient health care in pregnant women of Udhagamandalam population.

\section{CONCLUSION}

These results support the fact that those pregnant women whose vitamin $\mathrm{D}$ levels were less, tend to have lower levels of hemoglobin, red blood cells, iron, ferritin, hematocrit, mean cell volume and transferrin saturation. Further investigation needs to be conducted to evaluate whether there 
is a direct causal effect of vitamin D deficiency and iron deficiency anemia.

\section{ACKNOWLEDGEMENT}

We thank and acknowledge the support provided by the authorities of Government District Headquarters Hospital, Udhagamandalam and express our gratitude to all the study participants.

\section{CONFLICT OF INTEREST}

The authors declare no conflict of interest.

\section{ABRREVIATIONS}

IDA: Iron deficiency anemia; CKD: Chronic Kidney disease; MCV: Mean cell volume; MCH: Mean corpuscular hemoglobin; MCHC: Mean corpuscular hemoglobin concentration; TIBC: Total iron binding capacity.

\section{REFERENCES}

1. Nair R, Maseeh A. Vitamin D: The "sunshine" vitamin. J Pharmacol Pharmacother. 2012:3(2):118-26.

2. Kumari R, Bharti RK, Singh K, Sinha A. Prevalence of Iron Deficiency and Iron Deficiency Anaemia in Adolescent Girls in a Tertiary Care Hospital. J Clin Diagnostic Res. 2017;11(8):10-2.

3. Abbaspour N, Hurrell R, Kelishadi R. Review on iron and its importance for human health. J Res Med Sci. 2014;19(2):164-74.

4. Smith EM, Tangpricha V. HHS Public Access. Curr Opin Endocrinol Diabetes Obes. 2015;22(6):43208

5. Santoro D, Caccamo D, Lucisano S, Buemi M, Sebekova K, Teta D, et al. Interplay of vitamin $D$, erythropoiesis and the renin-angiotensin system. Biomed Res Int. 2015;2015:145828.

6. Suh YJ, Lee JE, Lee DH, Yi HG, Lee MH, Kim CS, et al. Prevalence and Relationships of Iron Deficiency Anemia with Blood Cadmium and Vitamin D Levels in Korean Women. J Korean Med Sci. 2016;(31):25-32.

7. Qader EA, Alkhateeb NE. Vitamin D Status in Children with Iron Deficiency and/ or Anemia. Int J Pediatr. 2016;4(9):3571-77.

8. Lee JA, Hwang JS, Hwang IT, Kim DH, Seo JH, Lim JS. Low Vitamin D Levels Are Associated with Both Iron Deficiency and Anemia in Children and Adolescents. Pediatr Hematol Oncol. 2015;32(2):99-108.

9. Hollis B, Johnson D. Vitamin D supplementation during pregnancy: Double blind, randomized clinical trial of safety and effectiveness. J Bone Miner Res. $2011 ; 26(10): 2341-57$.
10. Bener A, Salameh KM, Yousafzai MT, Saleh NM. Pattern of Maternal Complications and Low Birth Weight: Associated Risk Factors among Highly Endogamous Women. ISRN Obstet Gynecol. 2012;2012:540495.

11. Bener A, Abdulla OAA, Al-Hamaq, Saleh NM. Association between vitamin D insufficiency and adverse pregnancy outcome: global comparisons. Int JWomens Health. 2013;5(9):523-31.

12. Sim JJ, Lac PT, Liu ILA, Meguerditchian SO, Kumar VA, Kujubu DA, et al. Vitamin D deficiency and anemia: A cross-sectional study. Ann Hematol. 2010;89(5):447-52.

13. Zughaier SM, Alvarez JA, Sloan JH, Konrad RJ, Tangpricha V. The role of vitamin D in regulating the iron-hepcidin-ferroportin axis in monocytes. J Clin Transl Endocrinol. 2014;1(1):e19-25.

14. Langer AL, Ginzburg $Y Z$. Role of hepcidin-ferroportin axis in the pathophysiology, diagnosis and treatment of anemia of chronic inflammation. Hemodial Int. 2017:21(6):S37-46.

15. Webb AR, Pilbeam C, Hanafin N, Holick MF. An evaluation of the relative contributions of exposure to sunlight and of diet to the circulating concentrations of 25-hydroxyvitamin $\mathrm{D}$ in an elderly nursing home population in Boston. Am J Clin Nutr. 1990;51(6):1075-81.

16. Wacker M, Holick MF. Sunlight and Vitamin D. A global perspective for health Dermatoendocrinol. 2013;5(1):51-108.

17. Alvarez JA, Wasse $H$, Tangpricha V, Disease K, Quality O. Vitamin D supplementation in pre-dialysis chronic kidney disease - A systematic review. Dermatoendocrinol. 2012;4(2):118-27.

18. Bikle DD. Vitamin D insufficiency/deficiency in gastrointestinal disorders. J Bone Miner Res. 2007;22 (SUPPL 2):50-4

19. Bodnar LM, Simhan HN, Powers RW, Frank MP, Cooperstein E, Roberts JM. High prevalence of vitamin $D$ insufficiency in black and white pregnant women residing in the northern United States and their neonates. J Nutr. 2007; 137(2):447-52

20. Merewood A, Mehta SD, Chen TC, Bauchner $H$, Holick MF Association between vitamin D deficiency and primary cesarean section. J Clin Endocrino Metab. 2009;94(3):940-5.

21. Bowyer L, Catling-Paull C, Diamond T, Homer C, Davis G, Craig ME. Vitamin D, $\mathrm{PTH}$ and calcium levels in pregnant women and their neonates. Clin Endocrinol (Oxf). 2009;70(3):372-7.

22. Harinarayan CV, Holick MF, Prasad U V, Vani PS, Himabindu G. Vitamin D status and sun exposure in India. Dermatoendocrinol. 2013;5(1):130-41.

23. Lips P. Interaction between vitamin D and calcium. Scand J Clin Lab Invest Suppl. 2012;72(243):60-4

24. Thomas CE, Guillet R, Queenan RA, Cooper EM, Kent TR, Pressman EK, et al Vitamin D status is inversely associated with anemia and serum erythropoietin during pregnancy. Am J Clin Nutr. 2015;102(5):1088-95.

25. Iraj B, Ebneshahidi A, Askari G. Vitamin D deficiency, prevention and treatment. Int J Prev Med. 2012;3(10):733-6.

26. Bener A, Al-Ali M, Hoffmann GF. High prevalence of vitamin D deficiency in young children in a highly sunny humid country: a global health problem. Minerva Pediatr. 2009;61(1):15-22. 